In the pre-Petrine period the repertoire of registers of the written language had been realized primarily by the varying combination of genetically Church Slavonic and East Slavic elements. Accordingly, it was just these elements, relating to different spheres of social consciousness, that made up the linguistic material on which the symbolic dimension of language was constructed. The elements' provenance did not in and of itself define their social and cultural connotations - it was not their provenance itself that was important, but their role in the linguistic consciousness of their carriers, that is, not their genetic but their functional parameters. As comparative historical analysis shows, particular elements took on the role of symbolic indicators of either traditional religious culture or of secular innovation not because of their origin (East Slavic, South Slavic or other), but because their carriers (who had no inkling of comparative historical issues!) perceived them as characteristic of particular linguistic registers, i.e., as bookish or non-bookish, normative or non-normative, and so on. In order to reveal how language participates in social and cultural processes, its prehistory must reveal not the etymological but the functional role of linguistic elements, their hermeneutic status in the linguistic consciousness of speakers and writers. Hence in examining that prehistory, we seek traces of how their functional relationships developed out of the diversity of linguistic elements of various origins, and how the functional particular acquired particular symbolic meanings.

\title{
2. The Functional Reconceptualization of Genetically Heterogeneous Elements in the History of Russian Writing
}

The function of Church Slavonic in the world of Slavia Orthodoxa is often juxtaposed to the functioning of Latin in Catholic countries (on the history of such juxtapositions and their parameters, see Keipert 1987). However, the relationship between autochthonous and imported linguistic means in the two situations is completely dissimilar. In the last analysis, the dissimilarity may be explained by the different ways the languages were taught: Latin was assimilated via grammar and with a dictionary, while Church Slavonic via the Psalter and prayer book, which were learned by heart (see Tolstoi 1963, 259-64; Tolstoi 1976, 178-9). Learning Latin in medieval Germany or Ireland is typologically similar to learning language in school today. Learning Church Slavonic in Slavic lands was a fundamentally different experience, at least through the seventeenth century: pupils learned to read 
by rote (po skladam), reading and repeating texts and comprehending them through the resources of their native tongue. The nature of the acquisition of the written language also defined the place which these memorized elements of the bookish language occupied in the pupils' linguistic experience, the basis for which served the spoken language that they had assimilated with their mother's milk.

The surviving information about learning the bookish language in ancient Rus' is scarce and fragmentary, and for the eleventh and twelfth centuries direct evidence is completely lacking. Nevertheless one may reconstruct the corresponding phenomena with some degree of certainty, relying on comparative material and on later evidence. The basic means of learning language was reading by "po skladam" ("by syllables"). The procedure was strictly regimented and was considered sacred. ${ }^{1}$ It began and ended with prayer and was seen as a kind of introduction to Christian life. The special importance of correct and comprehensible reading was conditioned by the fact that the failure to follow the rules of reading could, from the point of view of Eastern Slavic bookmen, lead to heretical error. (See the "Instructions for Teachers How to Teach Children Literacy and How Children Can Learn Holy Writ and Understanding," foreword to the Psalter, Moscow, 1645; [...] Buslaev 1861, col. 1087-8).

By the early thirteenth century learning literacy po skladam may be considered generally accepted, as is evidenced by the writings (gramoty) of the boy Onfim (NBG, no. 199-210). The birchbark gramoty no.'s 199, 201, 204 and 206 belong to this period and include notations of sklady that correspond to what we find in later primers, and so may be taken as indication of an established system of primary education based on reading and memorizing them. After learning to read syllables came learning texts by heart, first prayers and then the Psalter. The first witness of this order of learning is those same gramoty of Onfim of the early thirteenth century. Thus, as N. A. Meshcherskii determined, one may make out several fragments of psalms on NGB no. 207 (Meshcherskii 1962, 108; cf. Zalizniak 1995, 387). As Zalizniak recently reported (in an oral communication), Onfim was also responsible for birchbark gramota no. 331, that also contains phrases from the psalms. These jottings indicate that the Psalter was used as a textbook for teaching basic literacy. The order of texts that were used is also indicated in the "Instructions for Teachers" of 1645 cited above ("in the beginning the letters, that is, the alphabet, then the prayerbook and the Psalter and other

A good description of the Russian method is found in a later but fully trustworthy source, a treatise by Epifanii Slavinstskii. [...] (NRB, Sof. 1208, 1.52-52 verso; cited in Uspenskii 1970, 82). 
divine books"), and a century and a half earlier in the epistle of Archbishop Gennadii to Metropolitan Simon (AI, I, no. 104, 148; cf. Upotreblenie knigi Psaltyr' 1857, 816-7).

As far as one can judge, elementary education culminated with learning the Psalter by heart. Indeed, we have no information at all that any grammar books, dictionaries or texts on rhetoric were used in language learning; in the oldest period of the Eastern Slavic literary tradition such texts were also completely absent. Methods of teaching including the use of grammar appeared in Muscovite Russia no earlier than the seventeenth century, and even at the start of the eighteenth were perceived as a novelty. In his edition of Smotritskii's grammar of $1721 \mathrm{~F}$. Polikarpov wrote:

...from ancient times it was (and still is) the custom for Russian educators of children and teachers to start with the primer, then [go to] the breviary and Psalter, and also to write using them, [and] some also teach reading the apostle. For the older ones they also have them read the Holy Bible and gospel and apostolic sermons and discuss the lofty ideas in these books. But that true instrument for understanding (that is, a grammar book) they do not show them, [a tool] with which to analyze every phrase and period and every word, and [to understand] how to put them in proper order, and which makes it possible to discuss the power of reason concealed in them. (Smotritskii 1721, Foreword, 1. 2 verso)

The traditional type of teaching clearly doesn't satisfy Polikarpov insofar as it doesn't include a mechanism for analyzing the memorized texts. This is what grammar supplies, and it is the desire to incorporate it into education that motivates Polikarpov to publish this edition. In the same foreword it also says that "after studying the breviary and Psalter (without which they [students] do not know how to learn the bookish language) this grammar with commentary (that is, with examples and explanation of its contents) should start [to be used]" (ibid, Foreword, 1. 5).

In this system of learning, new texts are acquired by means of the experience gained by reading previous works, that is, in the final analysis-when this experience is derived from the initial assimilation of bookish texts - based on the resources of the living language. On the basis of the habits developed in the process of reading, original texts are created. When we analyze these habits and see them as active mechanisms that ensure the understanding and the production of new texts, we need to emphasize two relatively autonomous processes: a) the mechanism of markers of bookishness or the mechanism of retabulation (pereschet), and b) the mechanism of orientation on texts.

The mechanism of markers of bookishness is based on the fact that individual elements of a bookish text are understood by relating them to 
elements of the living language. It is natural to conclude that for understanding a bookish text the pupil does not need to comprehend all of the connections among the various elements that are absent in his oral usage, since many are more or less synonymous to elements of that usage, although for many of them (for example, abstract lexicon) this kind of connection cannot be drawn. Relating the oral and written is needed only for those frequently repeating elements that form the structural basis of the statement. The established relationships may not form one-to-one correspondences, as in those cases when the set of categories of the living language differs from that of the bookish tongue. In these cases the grammatical semantics of the living language may be superimposed on the formal oppositions that are present in the bookish language.

In active mastery (that is, the production of texts) this mechanism will condition the reverse substitution of bookish forms for non-bookish ones, for example, simple preterits in the place of $\pi$-forms. Understandably, this mechanism will operate mostly when the author has something new to say, i.e, something he has not read many times, in this or another form. In this case, of course, the mechanism of retabulation will only involve particular elements, the ones with which difficulties arise and which can be easily retabulated, i.e., that have a formal correlation to elements of the non-bookish tongue. Such a correlation may be established between preterit forms of the bookish and non-bookish languages, between bookish participles functioning as secondary predicate and non-bookish gerunds, etc.

The mechanism of orientation on texts is clearly even more significant than that of retabulation. It conditions the reproduction of ready-made fragments of text, forms and constructions that the writer knows from the corpus of texts he has learned by heart. One must think that when someone has memorized a large corpus of texts (for example, the Psalter) that this significantly influences his cultural and linguistic consciousness, so different from ours in the modern age, and that this directly affects the character of his use of language. This person may automatically reproduce ready-made blocks of description (of situations, actions, feelings) following the pattern of bookish narration when writing about that which in one way or another has been processed in the texts he has memorized. In this instance the power of form-creating institutions that exist above individual discourse, and that will influence a person his whole life, is realized in a most explicit way; in this process individual consciousness is absorbed by the dominating mental tradition.

The given process may be seen as significant from a religious and cultural perspective, as it turns becoming literate into full-fledged 
indoctrination. This character of learning the bookish language as forming one's consciousness, and connected with learning a corpus of religious texts by heart, was amply clear to contemporaries, at least in the period when alternatives to this educational system began to arise. Thus the project for establishing schools that was proposed by the Catherinean Commission for Composing a New Law Code in the late 1760's suggested that elementary education be changed so that literacy be taught "both by church books and by civil laws." It presumed studying the civil alphabet together with the traditional Slavonic one. During the course of the entire eighteenth century people became literate using the church alphabet, while the civic was supplementary and only learned by small social groups (§ IV-2.2). The cited project (that was not put into practice) was an attempt to change this. In supporting the advisability of teaching "by civil laws" the authors of the project recalled that due to having learned the Psalter by heart "it happens that during normal conversations we approve or disapprove of things with whole verses from the psalmist; hence it will occur that we immediately see the consequences of any action [in terms of the Psalter]" (Sukhomlinov, I, 78). It was thus proposed to unite legal with religious indoctrination; according to the authors of the project, a person who been educated in this system would recall the laws punishing transgression just as automatically as they remembered formulations from the Psalter when evaluating life situations. The secularized power was trying to create a new state discourse parallel to the religious, making use of its mechanisms, which as we see were fully understood.

With this kind of education, a person's memory can evidently generate not only fragments of text describing a particular situation but also smaller textual elements, down to individual forms and constructions. Texts that have been learned by heart create a stock of images that may be reproduced when they are for some reason activated (usually connected with the imagery of the created text). The two mechanisms we have described, the mechanisms of retabulation and of orientation on texts, coexist and act simultaneously in creating new texts. Understandably, the mechanisms of retabulation will function in cases when for some reason memorized images are not activated. The simplest reason for this is the case when an author can't find material from this ready linguistic stock for a phrase that he wants to create, for example, because the content of this phrase goes beyond the subject matter represented there.

The differences in relating the mechanism of orientation on models and the mechanism of retabulation allow us to explain the genesis of various registers of the bookish language. If only the mechanism of orientation on 
texts is used, the product will be a standard Church Slavonic text that does not differ significantly from the texts of Holy Writ and the liturgy (i.e., the basic corps of bookish texts) that are being reproduced. We find this kind of language, for example, in Metropolitan Ilarion's "Sermon on Law and Grace" or in Russian supplements to service menalogia. Texts of this kind create their own tradition in whose framework new texts appear that have a similar function in the system of bookish literature. If the mechanism of retabulation is dominant, the result is a hybrid Church Slavonic text (see Zhivov 1988, 54-63), also oriented on the basic corpus of bookish texts but differing from it in a series of linguistic features. This kind of text also creates its tradition which in time gathers more and more new texts. Insofar as the intensive use of the mechanism of retabulation is caused by non-standard content (from the point of view of religious literature), the appearance of this tradition is evidently connected to the development of writing chronicles.

The action of these mechanisms determined the functional differences between registers of the bookish and non-bookish languages, i.e., in traditional terms, between the Church Slavonic and Russian languages. These two languages differentiate that which draws the main attention of users, those areas of difficulty that cause the problematic correlation of the bookish and conversational languages. This limited set of elements, requiring special analysis, are markers of bookishness in linguistic consciousness (as opposed to other elements of language that are not relevant). For example, the agreement of active participles that are absent in the non-bookish language may run into problems, both when the text is copied, when the copyist doesn't know if the form was used correctly, and when a new text is created and the author isn't sure what form to use. At the same time, other issues are unimportant, for example, pleophonic or non-pleophonic forms that don't require verification when being copied, and in creating a new text the choice of forms depends on a multitude of individual factors that have no relation to the bookish - non-bookish opposition.

Genetic heterogeneity that arose due to the assimilation of bookish material from other Slavic traditions served as the initial basis for the functional differentiation of linguistic elements. The fate of various elements that were categorized by the genetic opposition of "Eastern Slavic" versus "other Slavic" could be quite different. In some cases adaptation took place, that is, the assimilation of an Eastern Slavic element (an element of one of the East Slavic dialects) to the norm of the Russian recension of Church Slavonic and the simultaneous rejection of the corresponding element of other Slavic origin. In other cases the result could be the creation of a marker of bookishness, when the other Slavic element was preserved as part of the 
norm of the Russian recension and reconceptualized as a specific marker of the bookish character of the text. Finally, in still other cases, the opposition of Eastern and other Slavic became the source of variability: the opposition was neutralized and both elements became acceptable variants of the East Slavonic bookish language.

Adaptation took place primarily in orthography and inflexions. It was precisely orthographic and morphological norms that most clearly differentiated the various local recensions of Church Slavonic, while in the area of lexicon and syntax the notion of the normative was eroded; here the habits of bookish exposition that were basically similar for all recensions and not related to conversational usage were operative. Orthographic and morphological adaptation and the local norms that followed from it were motivated precisely on these levels by the very spread of literacy. Manuscripts traveled from one Slavic area to another and were copied and edited. Coexistence of manuscripts of various recensions and mistrust of the originals created the stimulus for each local tradition to unify orthographic and morphological features. The basis for this unification were rules that produced the "correct" form using linguistic information available to the copyist. This information derived from bookish pronunciation that had been established as a result of the church service's use of assimilated texts and as a rule excluding sounds and sound combinations that were alien to conversational pronunciation, as well as from aspects of the living language that could serve to verify bookish forms (see: Durnovo 1933; Lant 1950; Zhivov 1984; Zhivov 1986a). The very use of rules of this type conditioned the adaptation of Church Slavonic, making bookish forms dependent on those of the living language and assimilating them to local usage; traditional forms deriving from other Slavic literatures were accepted only in those cases when they coincided with local ones or could be correlated to them with the help of simple rules.

The functional reconceptualization of genetically heterogeneous elements was also accomplished thanks to the mechanism of retabulation, as the opposition of East and other Slavic elements was transformed into the juxtaposition of bookish and non-bookish elements, with the bookish ones no longer perceived as foreign. This perception reflected the way bookish elements were used in implementing the mechanism of retabulation; it not only juxtaposed the bookish and non-bookish languages but also correlated them. Actually, the grammatical semantics of the bookish language as fixed in the corpus of basic texts that were recopied and continually read was not unambiguously related to the grammatical semantics of the living language in any of the Slavic regions; and to the degree that the living 
languages developed this lack of correspondence only increased. Therefore the production of bookish texts on the basis of the mechanism of retabulation did not lead to the creation of texts whose grammatical system was fully analogous to that of the basic corpus. Their degree of closeness depended on the expertise of individual bookmen (in particular, their mastery of the basic corpus of texts), but was never absolute. As a result, original bookish texts to a greater or lesser extent reflected the grammatical semantics of the living language. ${ }^{2}$

Those processes of rethinking the genetically heterogeneous elements discussed above were connected to correlating the features of the two initial linguistic systems. The difference consisted in the fact that in the case of adaptation the genetically East Slavic elements displaced other Slavic ones as the norm of the East Slavic recension, while in the cases where the mechanism of retabulation came into play genetically non-East Slavic elements were preserved, serving as the bookish equivalent of certain forms or constructions of the bookish language. Such a direct correlation was possible or available, however, only in some cases. In cases where there was no direct correlation, genetically heterogeneous elements functioned as acceptable variants in the bookish language, and in this instance genetic characteristics lost their meaning, having been functionally reconceptualized in terms of variability.

A direct correlation may be established, as noted, with the help of general rules. In places where general rules were not formulated, there were no grounds for eliminating one of the elements (genetically Eastern Slavic or other). Moreover, the normal historical phonetic correlation could not serve as basis for formulating a general rule either. For the old Russian bookman these correlations were not a conscious factor, as they involved the linguistic material of their native language, for example, when there was a combination of $/ \mathrm{ro} /$ or $/ \mathrm{lo} /$ at the start of a word, but whether this was there "in place of the" proto-Slavic *or, *ol he waz incapable of figuring out. In some cases these combinations correlated to the initial $p a$ - or $\pi a$ - in bookish texts that were familiar to him, while in other cases the very same consistencies in the living language turned out to be related to the bookish ро- and ло- (cf. родити, роса, лобъзати, ловити). Therefore in his arsenal there could not be a rule of the

Thus, for example, after the imperfect disappeared from living East Slavic dialects the imperfect form in the bookish language could be related to the forms of the non-bookish language, and the result of this correlation was reflected in the character of its usage in original East Slavic texts that deviated from the main corpus (Holy Writ and the liturgy), and especially in relatively late texts (e.g., saints lives or chronicles of the fifteenth-sixteenth centuries) (cf. Zhivov 1986, 102-11). 
type: "where in the conversational language one hears $/ \mathrm{ro} /, / \mathrm{lo} /$ at the start of a word the bookish language has $p a-$. лa-." The lack of a rule meant the lack of a clear norm, and therefore работа and робота оr лакъть and локъть were permissible coexisting variants. Nothing in essence differentiates these cases from the situation with pleophonic and non-pleophonic lexemes. The writer was dealing with a colloquial combination of the /oro/ type, which in some cases was linked to the bookish pa- (порогъ - прагъ) but in others not (for example, порокъ [vitium, fault] but not*nракъ). And in this case the natural consequence of the lack of a general rule was the variability of pleophonic and non-pleophonic forms. In monuments that were copied variability of this kind would only occur occasionally. In creating original texts the lack of a general rule relating bookish and non-bookish elements was much more consequential, since variability became a constituent feature of the texts that made up the hybrid register of the bookish language.

Thus the reconceptualization of genetically heterogeneous elements took place in tandem with the development of the bookish tradition. In the composition of the Eastern Slavic recension of Church Slavonic these elements formed a unique mixture whose constituent parts were not juxtaposed as "ours" and "theirs" but led to a diversity of linguistic usages out of which later developed various written traditions. In some cases Eastern Slavic elements supplanted other Slavic ones in the bookish norm, and in others they were correlated with them, creating an opposition of bookish and non-bookish forms, and in a third instance both Eastern and other Slavic elements became acceptable variants. In all of these cases genetic categories were replaced by functional ones. This same mechanism also worked later on, when due to the development of the living language there appeared new differences between bookish and non-bookish usage. ${ }^{3}$ They also stimulate the process of adaptation (for example, accommodating bookish usage to the results of the fall and vocalization of reduced vowels - see Zalizniak 1986, 100; Zhivov 1984, 262-3) or are reconceptualized as markers of bookishness (for example, forms of the dual number) or as acceptable variants (for example, the gen. sg. masc. and neut. endings -аго/-ого in the declension of full-form adjectives).

\footnotetext{
New oppositions formed with special intensity after the final disintegration of Slavic linguistic unity in the late twelfth century (see Durnovo 1931). The active changes in the living language during this period led to a significant dissimilation (raspodoblenie) of the bookish and living languages and called forth a new series of functional reconceptualizations that marked a new period in the history of the bookish language. At the same time, the new oppositions broadened the diapason of choices available to East Slavic bookmen, and with this the possibility of separating out the various relatively independent written traditions expanded; some of them (for example, hymnology) could resist changes in usage more strongly than others (for example, hagiography).
} 
The reconceptualization of genetically heterogeneous elements in functional categories also influenced the character of linguistic consciousness. The bookish language was perceived not as an alien tongue that existed independently of the native language (in contrast to Latin) but as a cultivated variety of it. The mastery of the bookish language was superimposed onto native linguistic ways and united with them, forming the complex conglomerate of the speech habits of the written language whose concrete content depended both on the social and cultural status of the writer as well as on the type of written texts that he usually produced (these are understandably connected). Differing writing habits that primarily come from reading create different written traditions that have dissimilar cultural (and religious) importance. Linguistic phenomena that are characteristic of each of the written traditions (registers) acquire the same cultural weight as the tradition as a whole, and this significantly defines their role in the creation of the new type of literary language.

\section{The Main Registers of the Bookish Language and the Processes of Their Formation}

The main division in the written language of medieval Rus' was into bookish and non-bookish texts. Bookish texts were characterized primarily by their logically ordered and rhetorically organized syntax and their use of markers of bookishness (for example, forms of the imperfect or gerunds in agreement with their subjects). The syntax of non-bookish texts was oriented on the communicative situation (on what the addressee knows or doesn't know), so that the pragmatic structure plays a significantly greater role than logical organization, and markers of bookishness are not used (except for isolated cases and clichéd formulas). However, the division into bookish and non-bookish languages alone is not sufficient for describing the linguistic situation of medieval Rus' insofar as the linguistic features of both kinds of text are too heterogeneous to see them as opposing unities. This is one of the issues that prevents us from defining the linguistic situation of the Eastern Slavs as diglossia, as it does, for example, the coexistence of classical Arabic and modern Arabic languages. ${ }^{4}$

However, it seems that in the case of Arabic as well the division into "high" and "low" languages is not as unambiguous as one might conclude from classical descriptions of Arabic diglossia (see Ferguson 1959). Here too there are texts that significantly diverge from the bookish standard (Talmoudi 1984), but it is not clear if they form a discrete tradition. 